\title{
Change in Pattern of Muscle Activity Following Botulinum Toxin Injections for Torticollis
}

\author{
Douglas J. Gelb, MD, PhD, ${ }^{*}$ Don M. Yoshimura, MD, $\uparrow$ Richard K. Olney, MD, $\uparrow$ \\ Daniel H. Lowenstein, MD, $\dagger$ and Michael J. Aminoff, MD, FRCP $\dagger$
}

\begin{abstract}
Twenty patients with torticollis had electromyographic studies of their neck muscles performed before and after a series of local injections of botulinum toxin. The pattern of muscle activity changed after the injections, and this effect persisted even after head position had returned to baseline. Patients who did not experience any clinical benefit from the injections also demonstrated a change in the pattern of muscle activity. These results suggest that the underlying abnormality in torticollis usually involves a general motor program for head position, rather than the activity of individual neck muscles.
\end{abstract}

Gelb DJ, Yoshimura DM, Olney RK, Lowenstein DH, Aminoff MJ. Change in pattern of muscle activity following botulinum toxin injections for torticollis. Ann Neurol 1991;29:370-376

Local injections of botulinum toxin are effective in treating torticollis $[1-8]$. The beneficial effects are temporary, typically fading after 1 to 3 months. In an earlier study [8], some of our patients reported that their symptoms had returned to baseline even though originally prominent muscles had become flaccid after injection. This suggested that the same abnormal head posture was now being produced by a different pattern of muscle activity. This possibility would be consistent with what is currently known about neck movements in normal subjects.

The control system for neck movement has been called overcomplete, or overspecified, in that there are many more muscles available than necessary to accomplish the required movements $\{9,10]$. Because of this feature, any given neck movement could in principle be produced by a large number of different patterns of muscle activity [11]. Theoretical models have been developed to explain how the nervous system might "choose" from among the large number of possibilities $[9,12]$, and experimental studies have demonstrated that for any particular task, each neck muscle participates in an identifiable and repeatable manner $[10,13]$. Thus, despite the overcomplete nature of the system, the same pattern of neck muscle activity is observed whenever an animal is required to achieve a given head position while performing a given task. By varying the task, however, a different pattern of neck muscle activ- ity may be seen to produce the same head position. This has been demonstrated by comparing reflex and voluntary neck movements in cats $[10]$, and by varying the force against which human subjects were required to stabilize their head position $[10,13]$.

Based on these experimental results, one could predict that injection of botulinum toxin into neck muscles of a normal subject would result in a new pattern of muscle activity for any given head position. It is difficult to predict what would occur in a patient with torticollis, however, because the parhogenesis of torticollis is not understood. If torticollis is due to an abnormal motor program, then one might predict that a new pattern of muscle activity would emerge to produce the same abnormal head position despite the injection of botulinum toxin into previously overactive muscles. On the other hand, if torticollis is due to a relatively selective overactivity of individual neck muscles, then no persistent change in the pattern of muscle activity following botulinum toxin injections would be expected.

These two alternatives have significant implications, both for understanding the pathophysiology of torticollis and for predicting the likelihood of persistent clinical benefit from local injections of botulinum toxin. We decided to investigate this issue by directly comparing the pattern of muscle activity before and after injections of botulinum toxin.
From the *Department of Neurology, University of Michigan, Ann Arbor, MI, and the †Department of Neurology, University of California at San Francisco, San Francisco, CA.

Received May 21, 1990, and in revised form Aug 1. Accepted for publication Sep 27,1990 .
Address correspondence to Dr Gelb, 1914/0316 Taubman Center, Department of Neurology, University of Michigan, 1500 Last Medical Center Drive, Ann Arbor, MI 48109-0316. 


\section{Materials and Methods}

The treatment design was similar to that used in our earlier study [8], but involved a different group of patients.

\section{Patients}

Twenty-two patients, 13 women and 9 men, were enrolled in the study. Two patients dropped out of the study because they observed no benefit from the injections, and experienced mild dysphagia; 1 of these patients had completed only one injection session and the other had completed two. These patients were considered to be treatment failures in our analysis of clinical response rates, but they were not included in our analysis of electromyographic (EMG) changes. The mean age of the 20 patients who completed the study was 54 years (range, 36 to 70 years), and the mean duration of illness was 8.4 years (range, 1 to 23 years). As in our previous study, patients were given the option of stopping all medications 1 month before entering the study or continuing on their current drug regimen without making any changes during the course of the study; all but 1 chose to do the latter.

\section{Injections}

The muscles that were thought to be most actively contributing to the abnormal head position, either because they were tense in the resting position on clinical examination or because EMG testing demonstrated an abnormal interference pattern, were selected for injection. These were chosen from among three pairs of muscles: the sternocleidomastoid, trapezius, and splenius capitis muscles on each side. Most patients had either three or four muscles injected; 3 patients had five muscles injected, 1 patient had only two muscles injected, and 1 patient had all six muscles injected. Toxin was injected into two to eight sites per muscle, distributed evenly along the length of the muscle. Tsui (personal communication, 1987) had previously determined that injecting one or two sites near the middle of the muscle achieved the same effect as injecting multiple sites throughout the length of the muscle. We chose to inject multiple sites because it permitted a smaller volume per injection site, minimizing patient discomfort. The same muscles and injection sites were used at all sessions for any given patient. There were four injection sessions for each patient. At one session the patient received placebo (saline solution), and at the others the patient received three different doses of botulinum toxin: a base total dose of 120 to 140 units, and half and twice this base dose. At no session did any patient receive more than a total of 280 units, or 180 units to any one muscle.

\section{Injection Scbedule}

For each patient, the four injection sessions (one placebo, three different doses of toxin) occurred in random order known to some of the investigators but not the patient or the electromyographer. After each injection session, the patient was seen every 4 weeks, and not reinjected until any benefit (either subjective or objective; see below) from the preceding injection had completely disappeared.

\section{Clinical Evaluation}

SUBJECTIVE. At each clinic visit, patients were asked to rate separately the degree of pain and the severity of the head movements they had been experiencing, using a scale of 1 to 10 for each, with a score of 5 being arbitrarily designated as the baseline state on entering the study. These two scores were then summed to provide a composite subjective scale. As in our previous study, changes from baseline of greater than $20 \%$ were considered to be "substantial."

OBjeCtIVE. Patients were videotaped at the time they entered the study and 4 weeks after each injection session, following the standard filming protocol described in our previous paper. The videotapes were rearranged in random order by the photographer after completion of the study and scored independently by the investigators, who were thus "blinded" with respect to the order of tape presentation. As before, we used the numerical scoring system of Tsui and colleagues $\{1\}$ :

$T=\left[(R+L+E) \times D_{s}\right\}+\left[U \times D_{u}\right]$

where $\mathrm{T}$ is total score, $\mathrm{R}$ is rotation $\left(0=\right.$ absent, $1=<15^{\circ}$, $2=15^{\circ}$ to $\left.30^{\circ}, 3=>30^{\circ}\right) ; \mathrm{L}$ is lateral head tilt $(0=$ absent, 1 = mild, $2=$ moderate, 3 = severe); $E$ is shoulder elevation or depression ( $0=$ absent, $1=$ mild, $2=$ severe); $\mathbf{U}$ is unsustained movement, such as tremor or jerk $(0=$ absent, $1=$ present); and $D_{s}$ and $D_{u}$ are the durations of sustained and unsustained movements, respectively ( $1=$ intermittent, 2 = continuous). The same scoring system was also used to evaluate the patients at each clinic visit to determine whether any objective benefit from a previous injection persisted. As in our previous study, changes in objective score of at least 3 points were considered to be "substantial."

\section{Electrophysiological Tecbniques}

Each patient was evaluated electrophysiologically at the time of entry into the study and again 4 to 8 weeks after the final injection (in 1 patient, the follow-up EMG was performed 1 week after the final injection, and in 2 patients, it was performed 4 weeks after the third injection). A six-channel EMG recording was collected on a polygraph, with three muscle pairs being studied. Surface electrodes were used to record the activity of the trapezius and sternocleidomastoid muscles on each side, and monopolar needle electrodes were used to record activity of the splenius capitis muscles in reference to surface electrodes placed over the $C 7$ spinous process. Recordings were made on all patients while they were sitting erect, with the head in the spontaneously abnormal position, and then also with the head maintained facing forward so that the torticollis was resisted voluntarily for approximately 30 seconds. All six muscles were studied in every patient at each session, regardless of the number of muscles injected. Clearly, it would be optimal to study even deeper muscles as well, but this is not practical in human subjects. Our goal was not to define the precise pattern of muscle activity responsible for the abnormal neck posture, but to determine whether the pattern changed after botulinum toxin injections.

Because equipment to rectify and integrate the EMG was not available to us, we devised a descriptive scoring system to grade the level of muscle activity. Thus, each muscle's interference pattern was graded on a scale of 0 to 3 to give each muscle an EMG score. A score of 3 was assigned when 
Table 1. Number of Patients Showing Response to Botulinum Toxin

\begin{tabular}{|c|c|c|c|c|c|}
\hline Response & $\begin{array}{l}\text { Low } \\
\text { Dose }\end{array}$ & $\begin{array}{l}\text { Intermediate } \\
\text { Dose }\end{array}$ & $\begin{array}{l}\text { High } \\
\text { Dose }\end{array}$ & $\begin{array}{l}\text { At Least One } \\
\text { Dose }\end{array}$ & Placebo \\
\hline $\begin{array}{l}\text { Subjective improvement } \\
\text { (Substantial) }\end{array}$ & $\begin{array}{r}11 \\
(6)\end{array}$ & $\begin{array}{r}15 \\
(7)\end{array}$ & $\begin{array}{l}13 \\
(11)\end{array}$ & $\begin{array}{l}17 \\
(14)\end{array}$ & $\begin{array}{l}8 \\
(1)\end{array}$ \\
\hline $\begin{array}{l}\text { Subjective detcrioration } \\
\text { (Substantial) }\end{array}$ & $\begin{array}{c}1 \\
(0)\end{array}$ & $\begin{array}{c}0 \\
(0)\end{array}$ & $\begin{array}{c}1 \\
(1)\end{array}$ & $\begin{array}{c}1 \\
(1)\end{array}$ & $\begin{array}{c}1 \\
(0)\end{array}$ \\
\hline $\begin{array}{l}\text { Objective improvement } \\
\text { (Substantial) }\end{array}$ & $\begin{array}{l}9 \\
(4)\end{array}$ & $\begin{array}{l}10 \\
(3)\end{array}$ & $\begin{array}{c}10 \\
(3)\end{array}$ & $\begin{array}{l}16 \\
(7)\end{array}$ & $\begin{array}{l}\text { NA } \\
\text { (NA) }\end{array}$ \\
\hline $\begin{array}{l}\text { Objective deterioration } \\
\text { (Substantial) }\end{array}$ & $\begin{array}{c}6 \\
(2)\end{array}$ & $\begin{array}{l}4 \\
(2)\end{array}$ & $\begin{array}{c}2 \\
(1)\end{array}$ & $\begin{array}{l}7 \\
(2)\end{array}$ & $\begin{array}{c}\mathrm{NA} \\
(\mathrm{NA})\end{array}$ \\
\hline
\end{tabular}

$\mathrm{NA}=$ not applicable (objective response defined as change from placebo score).

the EMG recording consisted of a nearly full interference pattern in which individual motor-unit discharges could not be recognized. A score of 2 was assigned if the EMG recording consisted of an interference pattern in which motor units continuously disrupted the baseline but in which individual motor units were often seen. A score of 1 was assigned if the EMG recording reflected nearly continuous recruitment of individually recognizable motor units that did not continuously disrupt the baseline. A score of 0 was assigned if individually recognizable motor units were not activated or were activated less than $10 \%$ of the time. A muscle assigned a score of 3 always had more prominent motor-unit activation than the corresponding muscle on the contralateral side. Scores were generally based on the activity recorded while the head was maintained facing forward. However, when the sternocleidomastoid corrected an abnormal head rotation or the ipsilateral sternocleidomastoid-splenius capitis pair corrected a contralateral head tilt, scoring of these muscles was undertaken when the head was in the spontaneously abnormal position. This was done to minimize any artifact due to voluntary activity of neck muscles compensating for the abnormal head position.

Three patients with torticollis who had never received injections of botulinum toxin served as control subjects for the electrophysiological studies, undergoing EMGs on two occasions 1 month apart.

\section{Results}

\section{Clinical Response}

The subjective and objective response rates (Table 1) were very similar to those found previously. Of the 22 parients who entered the study, $77 \%$ (17 patients) showed subjective improvement, substantial in $64 \%$ (14 patients). The corresponding numbers in our earlier study [8] were $80 \%$ (16 patients) and $55 \%$ (11 patients). Objective improvement (based on the "blinded" scores assigned at videotape review) was more frequent in the current study than previously, with 7 of the 22 enrolled patients (32\%) showing substantial objective improvement, as opposed to $15 \%$ (3 patients) in our prior study. Even so, this higher objective improvement rate was still not statistically significant for any individual toxin dose $(p>0.05$, Wil- coxon signed rank test). However, when a composite "treatment score" (the average of the three scores corresponding to the three different toxin doses) was compared with a "control score" (the average of the score at baseline and the score after placebo injection) for each patient, the objective improvement was statistically significant ( $p<0.01$, Wilcoxon signed rank test), in constrast to our previous study. This discrepancy between results using the composite treatment score and scores for individual toxin doses is apparent from inspection of Table 2: in 18 patients, the composite treatment score was lower ("better") than the control score, and in 2 patients, it was higher. For the lowest dose, scores fell for 10 patients and rose for 6 ; for the intermediate dose, scores fell for 11 patients and rose for 5; and for the highest dose, scores fell for $11 \mathrm{pa-}$ tients and rose for 4 .

Side effects and duration of action were similar to our previously published results: subjective benefit typically lasted 1 to 3 months, and the most commonly reported adverse effects were local pain (either at the injection sites or "strain" in nearby muscles), local weakness, and dysphagia.

\section{Electromyograpbic Results}

As expected, the EMG score of individual muscles changed after patients received the full course of botulinum toxin injections. The change in EMG score between bascline and follow-up studies for a given muscle was clearly related to the dose of botulinum toxin that had been injected into that muscle (Fig). Although the EMG scores were descriptive, they were assigned by an investigator who did not know which muscles had been injected, or the doses used, so this relationship was not due to biased scoring.

The relationship between dose and change in EMG score is also evident from Table 3 . Of the muscles injected with a base dose of 40 units or more, $81 \%$ of muscles showed a decrease in EMG activity, whereas only $39 \%$ of muscles injected with a base dose of 20 units or less did so. By contrast, among noninjected 
Table 2. Objective Scores for All Patients Based on Videotape Review

\begin{tabular}{|c|c|c|c|c|c|c|}
\hline Patient No. & Placebo & $\begin{array}{l}\text { Low } \\
\text { Dose }\end{array}$ & $\begin{array}{l}\text { Intermediate } \\
\text { Dose }\end{array}$ & $\begin{array}{l}\text { High } \\
\text { Dose }\end{array}$ & $\begin{array}{l}\text { Composite } \\
\text { Treatment Score }\end{array}$ & $\begin{array}{l}\text { Control } \\
\text { Score }^{b}\end{array}$ \\
\hline 1 & 8.0 & 9.7 & 8.0 & 7.0 & 8.2 & 9.0 \\
\hline 2 & 6.3 & 7.3 & 7.0 & 8.3 & 7.5 & 7.3 \\
\hline 3 & 14.7 & NA & 11.3 & 15.0 & 13.2 & 15.2 \\
\hline 4 & 6.7 & 5.7 & 5.7 & $\mathrm{NA}$ & 5.7 & 7.2 \\
\hline 5 & 7.7 & 11.7 & 12.0 & 12.7 & 12.1 & 9.5 \\
\hline 6 & 8.7 & 7.7 & 8.3 & 7.0 & 7.7 & 9.4 \\
\hline 7 & 12.0 & 12.7 & 12.3 & $\mathrm{I} 2.0$ & 12.3 & 12.4 \\
\hline 8 & 8.7 & 8.3 & 8.0 & NA & 8.2 & 8.7 \\
\hline 9 & 12.7 & NA & 11.0 & 8.7 & 9.9 & 13.0 \\
\hline 10 & 6.0 & 5.5 & 6.0 & 6.0 & 5.8 & 5.9 \\
\hline 11 & 6.0 & 11.7 & 12.0 & 4.0 & 9.2 & 9.5 \\
\hline 12 & 9.0 & 9.0 & 7.3 & 6.7 & 7.7 & 9.5 \\
\hline 13 & 10.0 & 6.7 & NA & 6.3 & 6.5 & 10.2 \\
\hline 14 & 10.7 & 11.7 & 8.3 & NA & 10.0 & 12.4 \\
\hline 15 & 8.7 & NA & 9.7 & 8.3 & 9.0 & 9.5 \\
\hline 16 & 9.3 & 6.0 & 6.0 & 8.0 & 6.7 & 8.3 \\
\hline 17 & 10.1 & 7.0 & 8.7 & 8.3 & 8.0 & 9.5 \\
\hline 18 & 14.0 & 9.0 & 8.0 & 11.3 & 9.4 & 13.7 \\
\hline 19 & 9.7 & 7.0 & NA & 5.7 & 6.4 & 11.0 \\
\hline 20 & 9.7 & 8.7 & 7.7 & 10.0 & 8.8 & 9.5 \\
\hline
\end{tabular}

${ }^{a}$ The composite treatment score is the mean of the scores corresponding to the three different doses of botulinum toxin.

${ }^{b}$ The control score is the mean of the score at baseline and the score after placebo injection.

$\mathrm{NA}=$ not available (patient missed the videotape session or tape was lost).

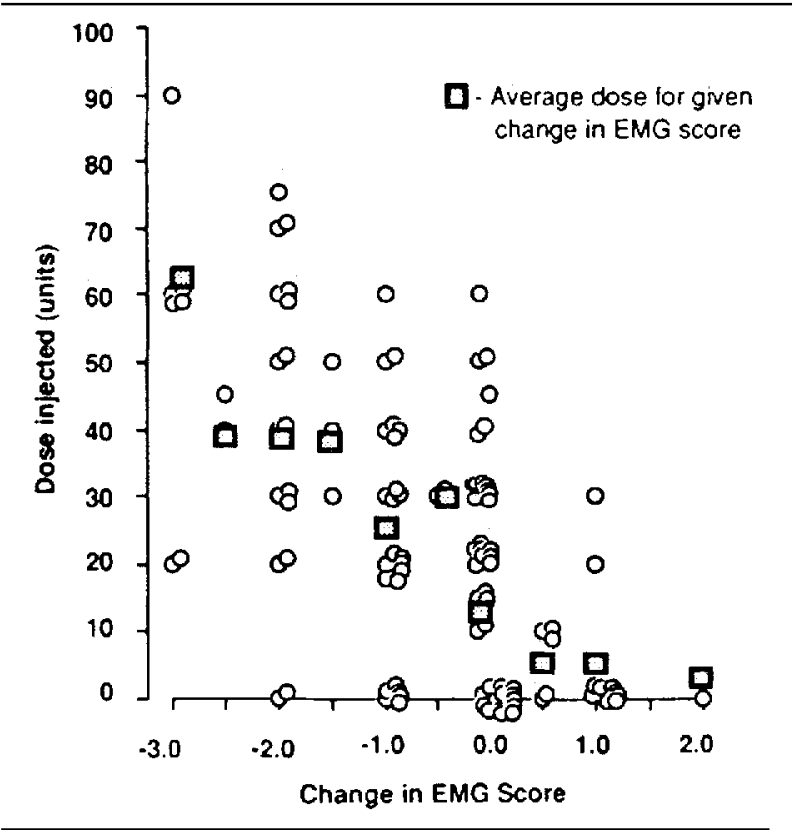

Change in EMG score (pretreatment score subtracted from score after treatment) plotted against the base dose of botulinum toxin injected. A negative value reflects a reduction in EMG activity for that muscle. The shaded squares represent the mean base dose for a given change in EMG score. muscles, an increase in EMG score occurred more commonly than did a decrease. In fact, over one-fourth $(27 \%)$ of noninjected muscles showed an increase in EMG activity, as opposed to only $6 \%$ of injected muscles. This difference was statistically significant $(z$ score for the difference between proportions, $z=3.14$, $p<0.01$ ).

Given the known mechanism of action of botulinum toxin at the neuromuscular junction, it should not be surprising to see a reduction in EMG score and a correlation with dose soon after an injection of botulinum toxin. However, this result would not necessarily be expected in the 6 patients who had received placebo injections at the final session. Since the study design required that all subjective and objective benefits of an injection session should have disappeared before the next injection session could take place, the follow-up EMG study in these patients (performed 2 to 5 months after the last injection of botulinum toxin) should not have reflected the acute effects of the toxin. Yet, even for these patients, injected muscles showed a reduction in EMG score (Table 4). It is unlikely that the placebo injections were somehow acting as a "conditioned stimulus," since so few patients showed substantial clinical improvement from placebo. Again, 27\% of noninjected muscles showed an increase in EMG activity. 


\begin{tabular}{lllc}
\hline & $\begin{array}{l}\text { Total No. of } \\
\text { Muscles }\end{array}$ & $\begin{array}{l}\text { No. of Muscles } \\
\text { with Decreased } \\
\text { EMG Activity }\end{array}$ & $\begin{array}{l}\text { No. of Muscles } \\
\text { with Incrased } \\
\text { EMG Activity }\end{array}$ \\
\hline Any dose & 79 & $47(59 \%)$ & $5(6 \%)$ \\
Dose $\geq 40$ units & 32 & $26(81 \%)$ & $0(0 \%)$ \\
$0<$ dose $\leq 20$ units & 28 & $11(39 \%)$ & $4(14 \%)$ \\
Dose $=0$ & 41 & $8(20 \%)$ & $11(27 \%)$ \\
(i.e., not injected) & & & \\
\hline
\end{tabular}

${ }^{a}$ The base dose was the intermediate dose injected into each muscle. At separate sessions, injections of half the base dose and twice the base dose were also administered. The follow-up EMG was performed after all injection sessions had been completed (with two exceptions; see text for details).

Table 4. Comparison of EMG Findings Following Injection of High Dose of Botulinum Toxin with Those Following Injection of Placebo

\begin{tabular}{|c|c|c|c|}
\hline & $\begin{array}{l}\text { Total No. of } \\
\text { Muscles }\end{array}$ & $\begin{array}{l}\text { No. of Muscles } \\
\text { with Decreased } \\
\text { EMG Activity }\end{array}$ & $\begin{array}{l}\text { No. of Muscles } \\
\text { with Increased } \\
\text { EMG Activity }\end{array}$ \\
\hline Injected muscles: highest dose last & 19 & $13(68 \%)$ & $1(5 \%)$ \\
\hline Injected muscles: placebo last ${ }^{\mathrm{a}}$ & 25 & $9(36 \%)$ & $1(4 \%)$ \\
\hline Noninjected muscles: placebo last ${ }^{\mathrm{a}}$ & 11 & $1(9 \%)$ & $3(27 \%)$ \\
\hline
\end{tabular}

${ }^{\text {a}}$ For patients who received their placebo injections 4 weeks before the EMG, the EMG findings in injected muscles and noninjected muscles are shown.

Thus, even after the original, abnormal head position had returned (and clinical examination showed normal muscle strength), EMG recordings still indicated a change from the baseline pattern of muscle activity.

The same conclusion follows from a consideration of those patients who failed to show substantial clinical improvement. Of the 13 patients who did not show substantial objective improvement with any dose, 11 nevertheless showed a convincing change in the pattern of EMG activity, defined as a change in EMG score in at least three muscles. In 7 of these patients, the most active muscle (based on EMG scores) before the injections was no longer the most active muscle after the injections. Similarly, there was a change in the most active muscle identified by EMG studies in 5 of the 6 patients who did not report substantial subjective improvement with any dose.

In contrast, in the 3 untreated control patients with torticollis, only $1(8 \%)$ of 12 muscles studied showed a reduction in EMG activity, and 1 muscle showed an increase in activity.

\section{Discussion}

This study corroborates our earlier results and those of other investigators [1-8], providing further evidence for the efficacy of local injections of botulinum toxin in the treatment of torticollis. As before, we were unable to show a statistically significant change in objective scores for any individual toxin dose, but we attribute this failure to the insensitivity of the scoring system, as we discussed previously [8, 14]. Similar problems are associated with the use of other scoring systems. Despite its limitations, we have continued to use this scoring system because it provides an objective measure by which our results can be compared with our previous results and those of other authors.

The main purpose of the current study was to compare the pattern of muscle activity before and after a series of injections of botulinum toxin. As expected, patients showed a general depression of EMG activity in injected muscles soon after the injections had taken place. The magnitude of this depression correlated with the dose of toxin injected. This depression of EMG activity persisted even after the clinical effects of the injections had disappeared (as shown by the patients who received placebo at their final injection sessions). Moreover, there was a tendency for muscles that had not been injected to show increased EMG activity, and this effect, too, was seen in patients who received placebo at their final injection session. With only one exception, these patients did not report any change from their baseline head position, and none was evident on examination (based on the numerical scoring system). Thus, the same abnormal head position was now associated with a different pattern of muscle activity. It is unlikely that this represents an inherent variability in muscle activity in patients with torticollis, or lack of reproducibility in our EMG scor- 
ing system, since untreated patients showed minimal change in muscle activity over time.

One might have expected that patients who failed to demonstrate a substantial clinical benefit from any of the injections would also fail to show an appreciable change in the pattern of muscle activity, since their abnormal head position remained constant throughout the study. Contrary to this expectation, a change in the pattern of muscle activity was evident in these patients as well. This was not simply an unmasking of muscles previously active at a low level, for the EMG scores revealed increased activity in individual muscles in the majority of these patients.

It is difficult to account for all of these findings purely on the basis of the direct effects of botulinum toxin at the neuromuscular junction. It is conceivable that the persistence of EMG changes beyond the duration of clinical response could simply mean that the EMG is more sensitive than clinical observation; the EMG changes in patients who never demonstrated any clinical change might be interpreted in this way also. However, the increased EMG activity in noninjected muscles in both of these groups of patients suggests a central, rather than a peripheral reorganization.

Were it not for this increase in EMG activity in noninjected muscles, our results could be questioned on methodological grounds. We recorded EMG activity in two head positions, and chose to base our scoring system primarily on the EMG activity recorded with the head maintained facing forward because it is the more useful one for assessing the muscles that move the head away from a normal position. Some of the EMG activity recorded with the head facing forward may have reflected compensatory activity of muscles not directly involved in producing the abnormal head position. We tried to correct for this (as discussed in the Material and Methods section), but if our correction was not sufficient, some of the reduction in EMG activity seen after injections of botulinum toxin may simply have reflected a reduction in this compensatory muscle activity. This interpretation cannot explain all of our results, however. Since injected muscles were always chosen as the ones whose action contributed to moving the head from the forward to the spontaneously abnormal position, the weakness of the injected muscles should always have made it easier for other muscles to maintain the head in a forward position. While this could result in reduced EMG activity being recorded from these muscles, there is no reason to expect increased activity in any muscles on this basis.

Because we studied activity in only six muscles, with the neck in only two positions, the present study does not allow us to draw any conclusions regarding the nature of the motor program itself. It is conceivable, in fact, that head position is controlled by more than one motor program. For example, one program might control tonic activation of neck muscles while another could be related to changes in head position (analogous to the control system for saccadic eye movements). Obviously, more detailed observations would be necessary to investigate these issues. However, our observations were sufficient to demonstrate that the pattern of muscle activity changed after injections of botulinum toxin, and this was at least partly due to central reorganization.

As discussed in the introduction, this conclusion is consistent with the idea that torticollis results from an abnormal motor program. When the most active muscles are functionally denervated by local administration of botulinum toxin, this "program" may simply call on other muscles to achieve its ends. This conclusion also follows from the results of surgical series, where the abnormal head position eventually recurs despite selective rhizotomy, peripheral nerve section, or muscle section $[15,16]$.

If other muscles can indeed substitute for the injected muscles to produce the abnormal head position, it might be expected that all patients will eventually fail to benefit from repeated injections of botulinum toxin. However, this has not been our experience, nor that of other investigators [3]. Whereas some patients gradually lose their response to botulinum toxin, others continue to experience satisfactory results for at least several years. This may simply reflect a slower adaptation rate, and with continued follow-up these patients may also ultimately fail to respond to repeated injections. Alternatively, there may be two distinct categories of patients with torticollis, possibly reflecting separate pathogenetic mechanisms, or perhaps variations between patients in the degree to which their motor programs adapt to environmental perturbations. Those patients in whom the abnormal motor program produces relatively selective overactivity of certain muscles might experience persistent benefit from repeated injections. By contrast, for patients in whom the motor program abnormality is less dependent on the activity of any particular neck muscle, functional (or actual) denervation might be followed by a fairly rapid emergence of a new pattern of muscle activity.

The present study was not designed to address these issues, which remain speculative, but one clear practical result does emerge. We have demonstrated that the pattern of muscle activity in patients with torticollis may change after injections of botulinum toxin, and this should be suspected in patients who initially responded to injections but subsequently fail to do so. This issue could not be addressed directly in the present study, since each patient received a different dose of botulinum toxin at each injection session. An apparent reduction in efficacy could therefore have been a function of the change in dose. However, in patients who fail to respond to previously effective doses, we 
recommend performing EMG studies to identify the most active muscles, and adjusting injection sites accordingly.

\section{References}

1. Tsui JK, Eisen A, Mak E, et al. A pilot study on the use of botulinum toxin in spasmodic torticollis. Can J Neurol Sci 1985;12:314-316

2. Tsui JK, Eisen A, Stoessl AJ, et al. Double-blind study of botulinum toxin in spasmodic torticollis. Lancet 1986;2: 245-247

3. Tsui JK, Fross RD, Calne S, Calne DB. Local treatment of spasmodic torticollis with botulinum toxin. Can J Neurol Sci 1987; 14:533-535

4. Brin MF, Fahn S, Moskowitz C, et al. Localized injections of botulinum toxin for the treatment of focal dystonia and hemifacial spasm. Mov Disord 1987;2:237-254

5. Greene $\mathrm{P}$, Shale $\mathrm{H}$, Fahn $\mathrm{S}$, et al. Treatment of torticollis with injections of botulinum toxin. Neurology 1987;37(suppl):123 (Abstract)

6. Jankovic J, Orman J. Botulinum A toxin for cranial-cervical dystonia: a double-blind, placebo-controlled study. Neurology $1987 ; 37: 616-623$

7. Stell R, Thompson PD, Marsden CD. Botulinum toxin in spasmodic torticollis. J Neurol Neurosurg Psychiatry 1988;51: 920-923

8. Gelb DJ, Lowenstein DH, Aminoff MJ. Controlled trial of botu- linum toxin injections in the treatment of spasmodic torticollis. Neurology 1989;39:80-84

9. Pellionisz AJ, Peterson BW. A tensorial model of neck motor activation. In: Peterson BW, Richmond FJ, eds. Control of head movement. New York: Oxford University Press, 1988: 178-186

10. Keshner EA, Peterson BW. Motor control strategies underlying head stabilization and voluntary head movements in humans and cats. Prog Brain Res 1988;76:329-339

11. Abbs JH, Cole KJ. Neural mechanisms of motor equivalence and goal achievement. In: Wise SP, ed. Higher brain funcrions: recent explorations of the brain's emergent properties. New York: Wiley, 1987:15-43

12. Crowninshield RD, Brand RA. A physiologically based criterion of muscle force prediction in locomotion. J Biomechanics 1981;14:793-801

13. Keshner EA, Campbell D, Katz R'T, Peterson BW. Neck muscle activation parterns in humans during isometric head stabilization. Exp Brain Res 1989;75:335-344

14. Gelb DJ, Lowenstein DH, Aminoff MJ. Botulinum toxin type A in the treatment of spasmodic torticollis. Neurology 1989; 39:1404

15. Podivinsky F. Torticollis. In: Vinken PJ, Bruyn GW, eds. Handbook of clinical neurology, vol 6. Amsterdam: North-Holland, 1968:567-603

16. McCabe JJ. Surgical trearment of spasmodic torticollis. In: Marsden CD, Fahn S, eds. Movement disorders; neurology 2. London: Butterworth, 1982:308-314 